\title{
Standalone Self-Excited Induction Generator with a Three-Phase Four-Wire Active Filter and Energy Storage System
}

\author{
José Antonio Barrado \\ DEEEA-ETSE \\ Universitat Rovira i Virgili \\ Tarragona, Spain \\ Email: joseantonio.barrado@urv.cat
}

\author{
Robert Griñó \\ IOC-ETSEIB \\ Universitat Politècnica de Catalunya \\ Barcelona, Spain \\ Email: roberto.grino@upc.edu
}

\author{
Hugo Valderrama \\ DEEEA-ETSE \\ Universitat Rovira i Virgili \\ Tarragona, Spain \\ Email: hugo.valderrama@urv.cat
}

\begin{abstract}
This paper proposes a system, based on a selfexcited induction generator with a shunt electronic converter, to feed isolated three-phase and single-phase linear or nonlinear loads. The electronic converter is composed by a three-phase four-wire voltage source inverter (VSI) and, connected to its dc side, two dc/dc converters. The VSI compensates the current harmonics, the reactive power and the load unbalances. The first of the dc/de converters is a battery charger/discharger and the other converter dissipates the active power excess, through a chopper, so these dc/dc converters keep the active power balance of the complete system. The designed control architecture assures that, in steady state, the rms values of the voltages and the frequency remain at the their reference values. The simulated results show a good performance of the system under different loading conditions.
\end{abstract}

\section{INTRODUCTION}

The self-excited induction generator (SEIG) has some advantages over the synchronous generator, for example: brushless (squirrel-cage rotor), reduced size, rugged and low cost. However, the induction generator offers poor voltage regulation and its value depends on the prime mover speed, capacitor bank size and load characteristics [1].

The cage-type induction generators advantages have led to choose them as a suitable candidate for energy supply in rural communities and remote areas, where these machines can be driven using some renewable energy resources like wind energy or micro-hydropower.

When a three-phase four-wire SEIG feeds unbalanced and/or non-linear loads, the terminal voltage and stator currents are also unbalanced and may appear current and voltage harmonics that increase the power losses, create unequal heating and cause torque pulsation on the shaft of the generator. Besides this, unbalanced three-phase currents yield a current in the neutral conductor that causes more power losses and heating.

These problems can be solved using different electronic converter topologies and control architectures. This work proposes, as an improvement for the system studied in [2], to add a bidirectional converter between the active filter dc bus and a battery set to provide energy storage capability to the whole system. In this way, the multi-converter system can compensate the abovementioned effects and transfer the suitable value of power in either direction between the battery and its ac terminals. So, the whole system increases its efficiency and capability.

\section{SYSTEM DESCRIPTION}

The system under study consists of a standalone SEIG driven by a prime mover. The generator supplies a three-phase four-wire system containing any kind of load. The voltage and frequency control is achieved by means of an electronic converter connected to the generator terminals with the necessary control loops to regulate these electrical variables (Fig. 1).

The SEIG is a three-phase induction machine with a wyeconnected stator winding with its middle point connected to the system's neutral conductor. A three-phase shunt capacitor bank supplies a constant reactive power to the SEIG. Finally, a prime mover drives the squirrel-cage rotor at a speed higher than the synchronous one.

The electronic converter consists of a shunt active filter (AF) made up of a four-leg voltage source inverter (VSI) with a split-capacitor dc bus [3] and two dc/dc converters connected to this de bus.

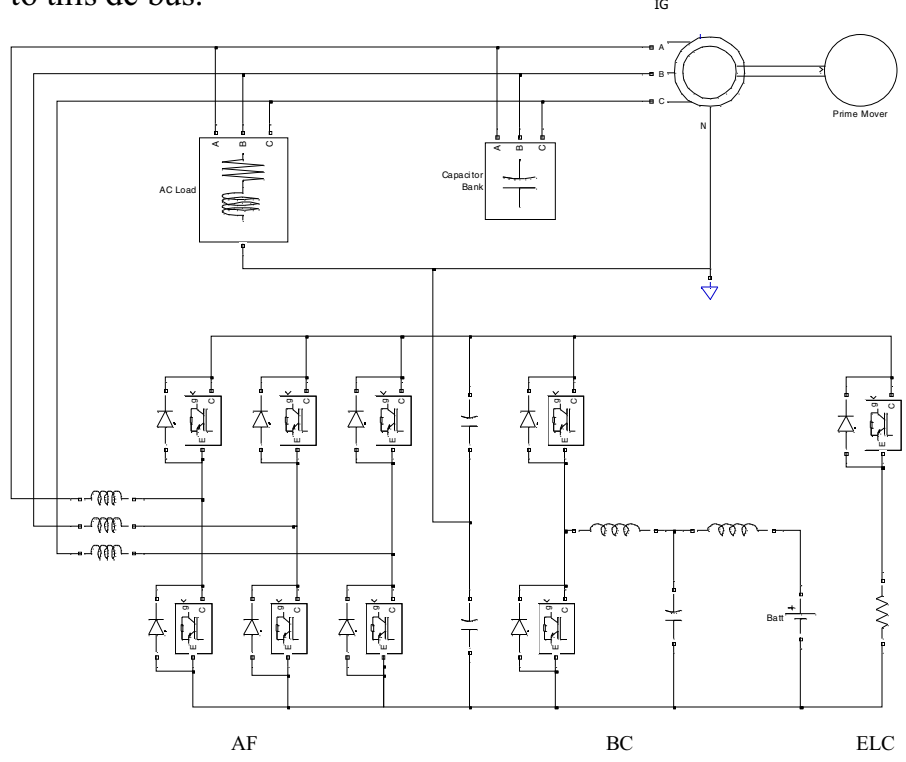

Fig. 1. Schematic diagram of three-phase four-wire system. 
One of this is an electronic load controller (ELC), made up of a chopper connected to a resistive load [4], and the other is a bidirectional current battery converter (BC) [5] which acts as a buck converter in the charging phase and as a boost converter in the discharging phase. This converter allows the battery to storage or to supply energy from or to the ac side of the system.

The proposed control architecture allows to the compound converter to eliminate current harmonics, to compensate reactive power and to balance the load at the SEIG terminals, as well as to storage or to inject energy depending on the ac load needs.

\section{MAthematical Model of System}

\section{A. Induction Generator Model}

The following equations describe the dynamic model of the squirrel-cage induction generator in the stationary dq0 reference frame [6].

The flux linkages per second taken into account the saturation effect are

$$
\begin{gathered}
\psi_{\mathrm{qs}}=\omega_{\mathrm{b}} \int\left[v_{\mathrm{qs}}+\frac{r_{\mathrm{s}}}{x_{\mathrm{ls}}}\left(\psi_{\mathrm{mq}}^{\mathrm{sat}}-\psi_{\mathrm{qs}}\right)\right] d t \\
\psi_{\mathrm{ds}}=\omega_{\mathrm{b}} \int\left[v_{\mathrm{ds}}+\frac{r_{\mathrm{s}}}{x_{\mathrm{ls}}}\left(\psi_{\mathrm{md}}^{\mathrm{sat}}-\psi_{\mathrm{ds}}\right)\right] d t \\
\psi_{\mathrm{qr}}^{\prime}=\omega_{\mathrm{b}} \int\left[\frac{\omega_{\mathrm{r}}}{\omega_{\mathrm{b}}} \psi_{\mathrm{dr}}^{\prime}+\frac{r_{\mathrm{r}}^{\prime}}{x_{\mathrm{lr}}^{\prime}}\left(\psi_{\mathrm{mq}}^{\mathrm{sat}}-\psi_{\mathrm{qr}}^{\prime}\right)\right] d t \\
\psi_{\mathrm{dr}}^{\prime}=\omega_{\mathrm{b}} \int\left[-\frac{\omega_{\mathrm{r}}}{\omega_{\mathrm{b}}} \psi_{\mathrm{qr}}^{\prime}+\frac{r_{\mathrm{r}}^{\prime}}{x_{\mathrm{lr}}^{\prime}}\left(\psi_{\mathrm{md}}^{\mathrm{sat}}-\psi_{\mathrm{dr}}^{\prime}\right)\right] d t
\end{gathered}
$$

The stator qd0 currents can be calculated as

$$
\begin{gathered}
i_{\mathrm{qs}}=\frac{\psi_{\mathrm{qs}}-\psi_{\mathrm{mq}}^{\mathrm{sat}}}{x_{\mathrm{ls}}} \\
i_{\mathrm{ds}}=\frac{\psi_{\mathrm{ds}}-\psi_{\mathrm{md}}^{\mathrm{sat}}}{x_{\mathrm{ls}}} \\
i_{0 \mathrm{~s}}=\frac{\psi_{0 \mathrm{~s}}}{x_{\mathrm{ls}}}=\frac{\omega_{\mathrm{b}}}{x_{\mathrm{ls}}} \int\left(v_{0 \mathrm{~s}}-r_{\mathrm{s}} i_{0 \mathrm{~s}}\right) d t
\end{gathered}
$$

The electromagnetic torque equation is

$$
T_{\mathrm{em}}=\frac{3}{2} \frac{P}{2 \omega_{\mathrm{b}}}\left(\psi_{\mathrm{ds}} i_{\mathrm{qs}}-\psi_{\mathrm{qs}} i_{\mathrm{ds}}\right)
$$

The rotor motion is given by

$$
T_{\mathrm{em}}=J \frac{2}{P} \frac{d \omega_{\mathrm{r}}}{d t}+T_{\mathrm{damp}}-T_{\mathrm{mec}}
$$

The magnetic saturation is the main factor for voltage buildup and its stabilization on SEIG. For machines with uniform air gap, the saturated value of the mutual flux linkage per second in qd-axes is given by

$$
\begin{aligned}
& \psi_{\mathrm{mq}}^{\mathrm{sat}}=x_{\mathrm{M}}\left(\frac{\psi_{\mathrm{qs}}}{x_{\mathrm{ls}}}+\frac{\psi_{\mathrm{qr}}^{\prime}}{x_{\mathrm{lr}}^{\prime}}-\frac{\Delta \psi_{\mathrm{mq}}}{x_{\mathrm{m}}}\right) \\
& \psi_{\mathrm{md}}^{\mathrm{sat}}=x_{\mathrm{M}}\left(\frac{\psi_{\mathrm{ds}}}{x_{\mathrm{ls}}}+\frac{\psi_{\mathrm{dr}}^{\prime}}{x_{\mathrm{lr}}^{\prime}}-\frac{\Delta \psi_{\mathrm{md}}}{x_{\mathrm{m}}}\right)
\end{aligned}
$$

Where

$$
\frac{1}{x_{\mathrm{M}}}=\frac{1}{x_{\mathrm{ls}}}+\frac{1}{x_{\mathrm{lr}}^{\prime}}+\frac{1}{x_{\mathrm{m}}}
$$

Assuming a proportional reduction in the mutual flux linkages of the qd-axes, the value of $\Delta \Psi_{\mathrm{mq}}$ and $\Delta \Psi_{\mathrm{md}}$ is determined from the following relationships

$$
\Delta \psi_{\mathrm{mq}}=\frac{\psi_{\mathrm{mq}}^{\mathrm{sat}}}{\psi_{\mathrm{m}}^{\mathrm{sat}}} \Delta \psi_{\mathrm{m}} ; \Delta \psi_{\mathrm{md}}=\frac{\psi_{\mathrm{md}}^{\mathrm{sat}}}{\psi_{\mathrm{m}}^{\mathrm{sat}}} \Delta \psi_{\mathrm{m}}
$$

Where the values of $\Delta \Psi_{\mathrm{m}}$ and $\Psi_{\mathrm{m}}^{\text {sat }}$ are obtained from the terminal voltage versus no-load stator current curve.

The model of induction generator, with saturated mutual flux linkage per second, is implemented with Simulink. It is divided in blocks that consider the transformations: abc-qd0 of the stator voltages and qd0-abc of the stator currents, and solve the previous equations (1) to (13): stator currents, flux linkages, magnetic saturation, torque and rotor speed [7].

\section{B. Electronic Converter Model}

Fig. 2 shows the electrical scheme of the electronic converter. The ac side of this system is made up of a threephase four-wire current controlled voltage source inverter (CCVSI), acting as active filter [8]. The three-leg converter topology with the neutral wire connected directly to the midpoint of the dc bus capacitors (split-capacitor dc bus) is preferred due to its lower number of power semiconductor devices with regard to the four-leg topology.

The CC-VSI is modeled by three switching functions ( $\mathrm{SA}$, $\mathrm{SB}$, and $\mathrm{SC})$ that determine the state of the IGBTs $\left(\mathrm{SA}_{\mathrm{P}}\right.$ to $\left.\mathrm{SC}_{\mathrm{N}}\right)$ in each branch of the bridge. Considering the commutation basic rules of converters, the switches of a branch must change in a complementary form.

As far as the dc/dc converters are concerned, the first one is a bidirectional converter for charging/discharging a battery. The two IGBTs of this battery converter are switching, in a complementary form, by means of SD function. This function is a PWM signal and its duty cycle value determines the battery current direction and magnitude. The second converter is a chopper, who switches a resistive load, and its only IGBT is switching by SE function.

The differential equations in each ac terminal of the converter, according to its respective switching functions, are

$$
\begin{gathered}
v_{x \mathrm{n}}=\mathrm{R}_{\mathrm{L} 3} i_{x}+\mathrm{L}_{3} \frac{d i_{x}}{d t}+e_{x \mathrm{n}}, \quad x=\{\mathrm{a}, \mathrm{b}, \mathrm{c}\} \\
e_{x \mathrm{n}}=\mathrm{S}_{y} v_{\mathrm{C} 1}-\overline{\mathrm{S}}_{y} v_{\mathrm{C} 2}, \quad x=\{\mathrm{a}, \mathrm{b}, \mathrm{c}\}, y=\{\mathrm{A}, \mathrm{B}, \mathrm{C}\}
\end{gathered}
$$


The ac side currents of CC-VSI must to follow their reference currents. For this purpose, three independent hysteretic current controllers working in closed loop generate the switching patterns for each branch of the converter.

The voltage of dc bus is calculated from the inductor currents at the VSI and the currents at dc/dc converters as follows

$$
\begin{gathered}
v_{\mathrm{dc}}=v_{\mathrm{C} 1}+v_{\mathrm{C} 2} \\
v_{\mathrm{C} 1}=\frac{1}{\mathrm{C}_{1}} \int\left(\mathrm{S}_{\mathrm{A}} i_{\mathrm{a}}+\mathrm{S}_{\mathrm{B}} i_{\mathrm{b}}+\mathrm{S}_{\mathrm{C}} i_{\mathrm{c}}-\mathrm{S}_{\mathrm{D}} i_{\mathrm{BC}}-\mathrm{S}_{\mathrm{E}} i_{\mathrm{Rdc}}\right) d t \\
v_{\mathrm{C} 2}=\frac{1}{\mathrm{C}_{2}} \int\left(\overline{\mathrm{S}}_{\mathrm{A}} i_{\mathrm{a}}+\overline{\mathrm{S}}_{\mathrm{B}} i_{\mathrm{b}}+\overline{\mathrm{S}}_{\mathrm{C}} i_{\mathrm{c}}-\mathrm{S}_{\mathrm{D}} i_{\mathrm{BC}}-\mathrm{S}_{\mathrm{E}} i_{\mathrm{Rdc}}\right) d t
\end{gathered}
$$

Due to the boost-type operation of the inverter, the $V_{\mathrm{dc}}$ set point must be greater than two times the peak value of ac phaseto-neutral voltages in order to obtain the desired operation.

The dc side currents of the VSI and its relationships with the ac side currents are expressed by

$$
\begin{gathered}
i_{\mathrm{dc}}=i_{\mathrm{C} 1}+i_{\mathrm{Cdc}} \\
i_{\mathrm{C} 2}=i_{\mathrm{C} 1}+i_{\mathrm{n}} \\
i_{\mathrm{a}}+i_{\mathrm{b}}+i_{\mathrm{c}}+i_{\mathrm{n}}=0
\end{gathered}
$$

The currents through the dc/dc converters are

$$
\begin{gathered}
i_{\mathrm{Cdc}}=i_{\mathrm{BC}}+i_{\mathrm{Rdc}} \\
i_{\mathrm{BC}}=\mathrm{S}_{\mathrm{D}} i_{\mathrm{Ll}} \\
i_{\mathrm{Rdc}}=\mathrm{S}_{\mathrm{E}} \frac{v_{\mathrm{dc}}}{\mathrm{R}_{\mathrm{dc}}}
\end{gathered}
$$

The differential equations of the battery converter are as follow

$$
\begin{gathered}
u_{1}=\mathrm{S}_{\mathrm{D}} v_{\mathrm{dc}} \\
u_{1}-v_{\mathrm{C} 3}=\mathrm{R}_{\mathrm{L} 1} i_{\mathrm{L} 1}+\mathrm{L}_{1} \frac{d i_{\mathrm{L} 1}}{d t} \\
v_{\mathrm{C} 3}=\frac{1}{\mathrm{C}_{3}} \int\left(i_{\mathrm{L} 1}-i_{\mathrm{Batt}}\right) d t \\
v_{\mathrm{C} 3}-v_{\mathrm{Batt}}=\mathrm{R}_{\mathrm{L} 2} i_{\mathrm{Batt}}+\mathrm{L}_{2} \frac{d i_{\mathrm{Batt}}}{d t}
\end{gathered}
$$

The chosen LCL topology for the filter allows a higher attenuation of the high frequency harmonic content in the injected current to the battery than the usual L filter.

\section{CONTROLler Description}

Fig. 3 shows the block diagram of the proposed control architecture. The controller forces the electronic converter to compensate the load current and to absorb a determinate value of active power from the system. Thus, the current supply from SEIG becomes sinusoidal, balanced and the values of voltage and frequency are maintained constant.

Therefore, the induction generator provides the active power demanded by the load and the other active power necessary to keep the voltage in the dc capacitors. This additional component determines a current value to cover the losses in the power converter (switching losses of IGBTs, leakage current of capacitors, etc), to supply the current of controlled dc load and to charge a battery. All this power changes cause voltage variations on the dc-link [9] that are corrected by the $\mathrm{dc}$ voltage regulator.

The main block of the proposed control is a three-phase PLL structure. A first PLL determines the fundamental frequency

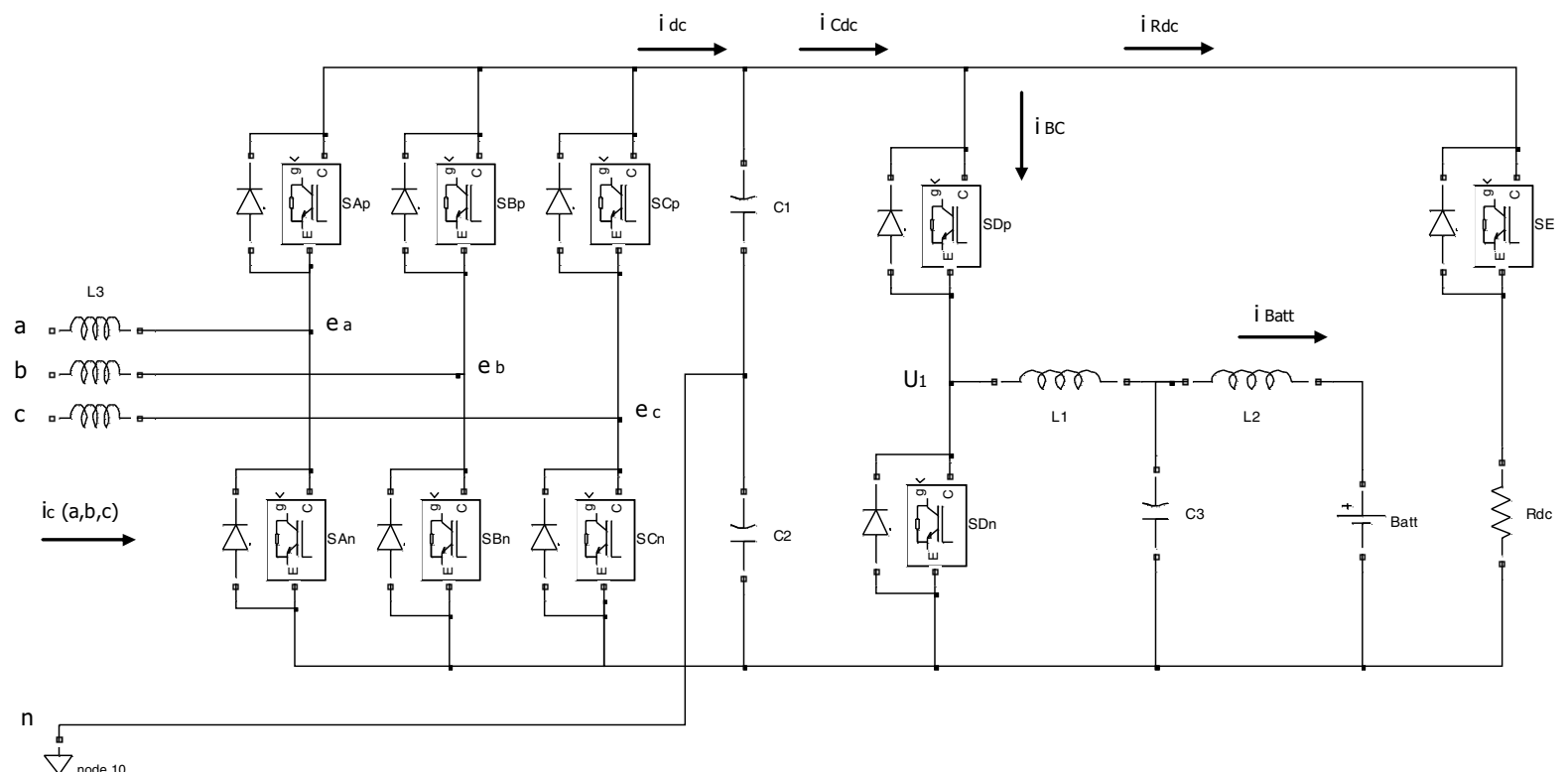

Fig. 2. Full electronic converter. 
and the synchronizing signals from the ac voltage. Another block has two three-phase PLL for extracting the magnitude and phase angle of fundamental positive-sequence of the voltage line and current load, respectively [10] [11].

From these two magnitudes and its phase difference, the block "magnitude to abc" generates the three-phase balanced active component of the load current, iLa (abc). To remark that these signals are sinusoidal and keep $120^{\circ}$ among themselves, they have equal amplitude and its frequency value is equal to the fundamental one.

The difference between the generated value, iLa $(a b c)$, and the measured load current, iL (abc), yields the reference current to compensate the reactive power, the unbalanced currents and harmonics of the three-phase four-wire general load [12].

The total reference current to apply on CC-VSI block, ic (abc)*, are the sum of the above component (compensated load current) and two other components: the signal icp (abc) and the signal icq $(\mathrm{abc})$.
The reference $\mathrm{icp}(\mathrm{abc})$ is the necessary active current to balance the active power in the whole system in order to maintain the desired frequency (frequency regulator) and to compensate the losses in the electronic converter (dc voltage regulator).

Therefore, the frequency regulator supplies an ac current magnitude in phase with ac voltage signals. These three-phase magnitudes yield an active power value that is equivalent to dc power. It is divided by the voltage value on dc bus, thus generating the reference current, icde, for $\mathrm{dc} / \mathrm{dc}$ converters. When the SEIG is working without ac load, this reference includes the battery current value (equivalent to $40 \%$ of the SEIG rated current) and the reference to the controlled dc load (corresponding to the remaining of the active power excess).

When an ac load is switched on to the SEIG the demand of generating power is increased; this yields a reduction in the rotor speed and, consequently, of the frequency value. So, the lower output signal of the frequency regulator forces to

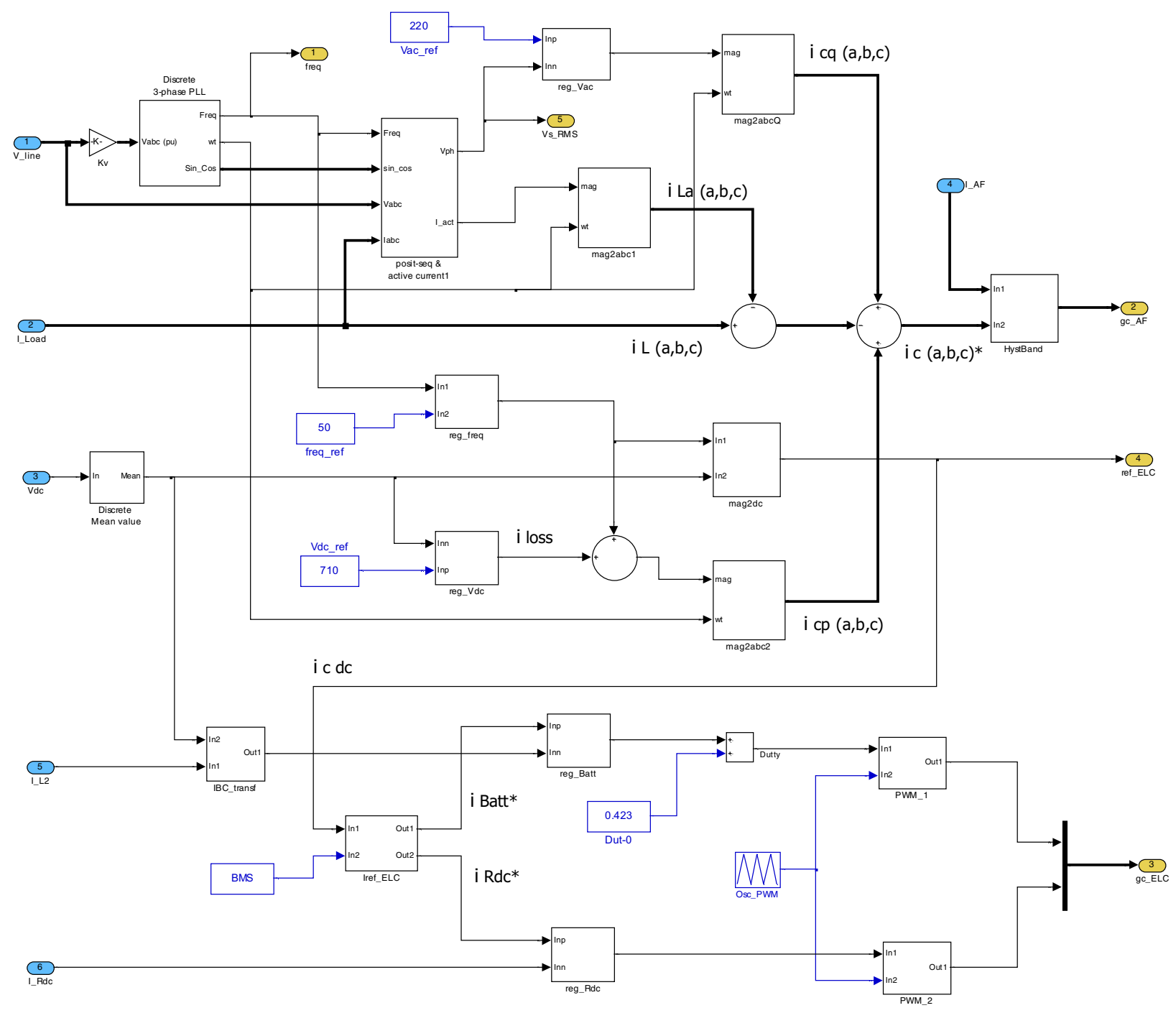

Fig. 3. Block diagram of the electronic converter control. 
decrease the current through the $\mathrm{dc} / \mathrm{dc}$ converters. First, it decreases the current corresponding to the power dissipated by the chopper and the battery keeps its value of charge current. But if this behavior is not enough the bidirectional converter decreases the battery charge current to a suitable value. If the ac load is higher, then this last converter forces the battery to inject a determinate value of current to the ac side of the system, through to the VSI.

Besides this, the slower feedback control loop of the dc voltage regulator gives another reference signal, iloss, to make the active filter to absorb an in-phase fundamental current to compensate the above mentioned voltage variation on dc side.

On the other hand, the signal $\mathrm{icq}(\mathrm{abc})$ is a reference current that sets the required reactive power for compensate the ac voltage variations on standalone induction generator. This reactive power is supplied by means of the electronic converter and the capacitor bank.

The ac voltage regulator calculates the above mentioned current component. It is important to emphasize that this current reference is in quadrature with the sensed three-phase voltage.

The three phase currents of the converter are controlled using a hysteretic controller for each branch (hysteresis band current control). Each controller acts over the corresponding difference between the reference currents of the converter, ic $(a, b, c)^{*}$, and the measured ac side currents, ic $(a, b, c)$. Its operation determines the gating signals to switch the respective IGBT of the VSI.

The closed loop control of the battery converter is obtained from a PWM current controller. The relation $\mathrm{Vbatt} / \mathrm{Vdc}$ and the signal from the battery regulator establish the duty cycle of the gating signal $S_{D}$. This value determines the state of the respective two IGBTs and consequently the magnitude and direction of battery current. Finally, the signal of the Rdc current regulator is connected to the input of another PWM current controller. The output of this controller determines the gating signal, SE, to switch the IGBT of the chopper. Thus, these two dc/dc converters and its controllers regulate the flow of active power in order to balance the active power of the whole system.

\section{Simulation Results}

This section shows the performance of the model by means some simulation results of the controlled system.

Fig. 4 shows the response of the system when a dynamic three-phase load is switched, plotting the following transient waveforms: line currents, frequency and rms voltage at the SEIG terminals, load currents, three-phase currents trough the ac side of converter, voltage on the dc bus, battery current and chopper mean current.

First SEIG works without ac load, so the dc/dc converters consume all the generated power. Most active power flows to the battery converter and chopper, only a small amount of this active power keeps the voltage level in the dc bus of this converter.
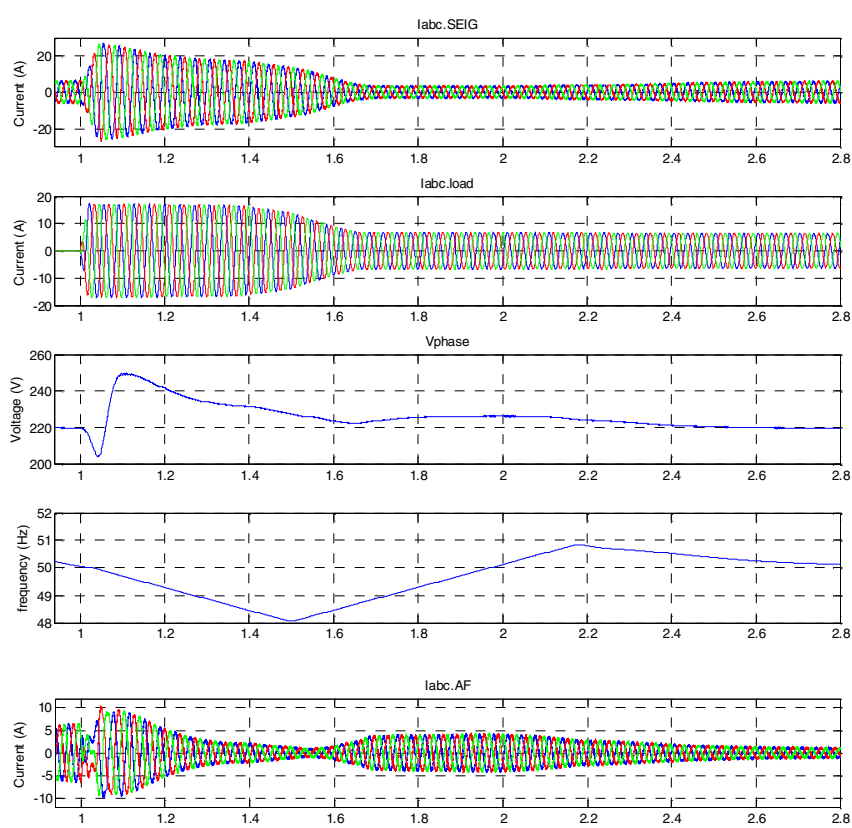

I.Bat
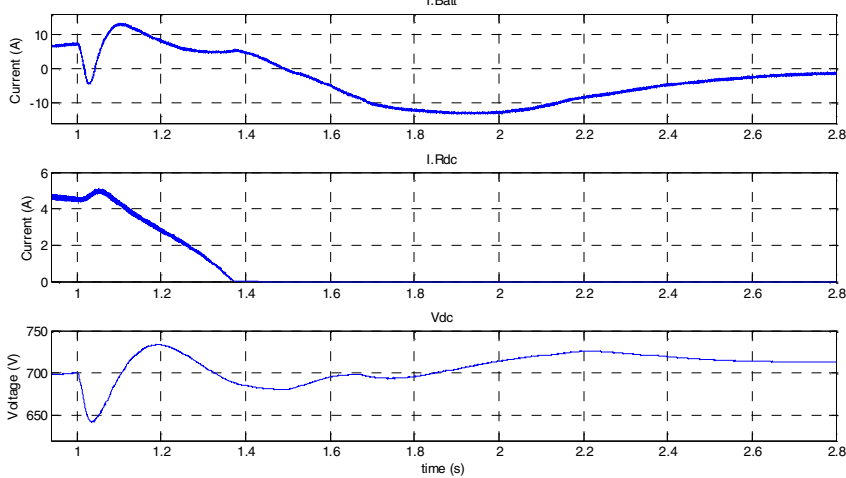

Fig. 4. Transient response of complete system when a dynamic three-phase load is connected.

The left side of Fig. 4 depicts the respective values of the ac and dc currents in the electronic converter.

At time 1 second, a dynamic balanced three-phase load is connected to the system. This action implies heavy variations of the ac and dc magnitudes on the SEIG and the electronic converter. However, the controller responds driving the magnitude and frequency of generated voltage to their reference values.

Fig. 4 also shows that the battery first stores and then injects a suitable value of current by means the controlled bidirectional battery converter. Consequently, the active power flows as a function of the ac load conditions. This possibility allows increasing the efficiency and availability of the proposed generating system.

Fig. 5 shows the behavior of the complete system with a single-phase inductive load and a non-linear load (three-phase rectifier bridge with a capacitive filter and a resistive load). The AF block of the converter compensates the neutral current and current harmonics that are due to the unbalanced and nonlinear nature of the ac load. 

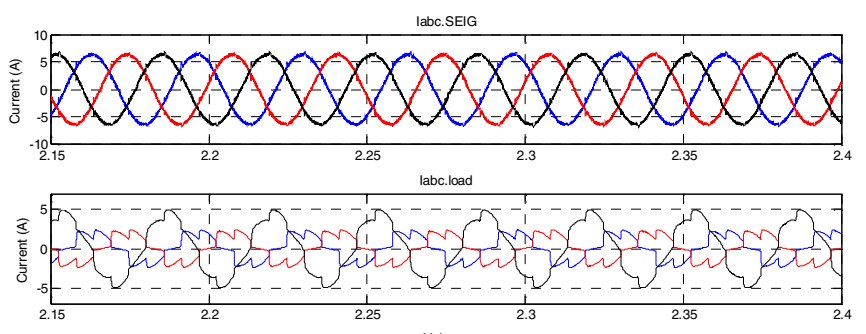

Vphase
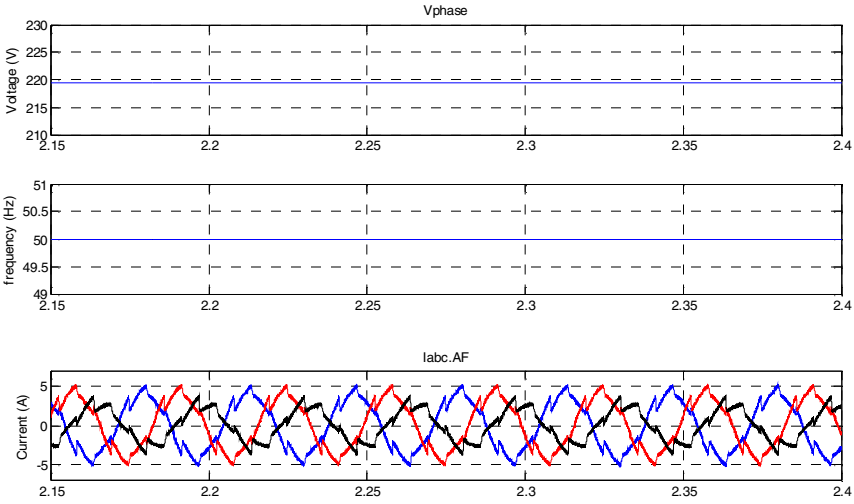

1. Batt

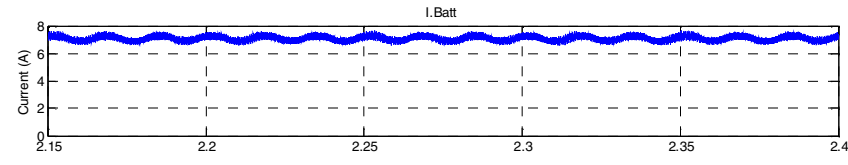

I. Rdo

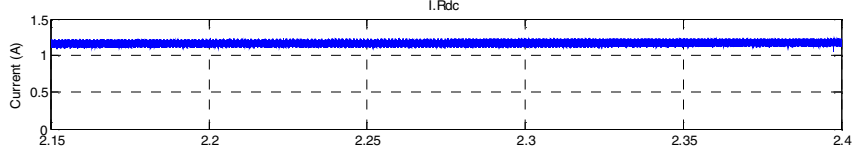

Vdc

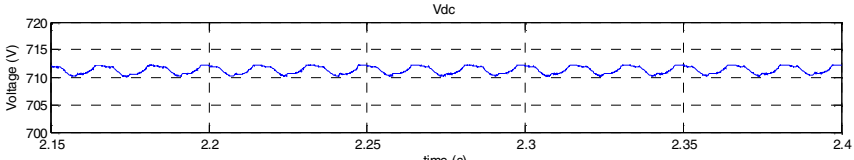

time $(s$

Fig. 5. Steady state waveforms of system supplying an unbalanced and non-linear load.

However, the neutral current causes an asymmetrical flow of current in the split-capacitor dc bus and, consequently, it yields a ripple in the dc bus voltage. Besides this, the load only consumes part of the generated power so the battery can absorb its maximum current value and the chopper dissipates the active power excess. Fig. 5 also shows the ac current waveforms, that are sinusoidal and balanced, the ac voltage rms value and the system's frequency.

\section{CONCLUSIONS}

This paper has presented a controller's architecture for a stand-alone SEIG driven with an unregulated turbine. It is made up of a three-phase four-wire shunt active filter with a bidirectional battery converter and a controlled dc load.

The AF topology allows to attenuate current harmonics, to compensate reactive power and to balance the stator currents while the energy storage system can store or inject active power, and the controlled dc load dissipates, if necessary, the rest of the generated power. So, the converter and its control loops allow to maintain the rated voltage and frequency under different loading conditions and increasing the efficiency and availability of system. The simulation results show a good performance and the efficiency of the whole system under different loading conditions.

\section{APPENDIX}

The values of the parameters used to obtain the simulation results are:

- Induction machine and capacitor bank:

$\mathrm{P}=4 \mathrm{~kW}, \mathrm{Vac}=220 \mathrm{~V}, \mathrm{f}=50 \mathrm{~Hz}, 4$ poles

Rs $=1.365 \Omega, R^{\prime} r=1.405 \Omega, L l s=L^{\prime} l r=5.839 \mathrm{mH}$

$\mathrm{Lm}=172.2 \mathrm{mH}, \mathrm{J}=0.013 \mathrm{~kg} \cdot \mathrm{m}^{2}, \mathrm{Cac}=3 \times 60 \mu \mathrm{F}$

- Electronic converter and battery:

$\mathrm{C} 1=\mathrm{C} 2=3000 \mu \mathrm{F}, \mathrm{C} 3=4.7 \mu \mathrm{F}$

$\mathrm{L} 1=3 \mathrm{mH}, \mathrm{L} 2=0.8 \mathrm{mH}, \mathrm{L} 3=5 \mathrm{mH}$

$\operatorname{Rdc}=72 \Omega, \quad$ Vbatt $=300 \mathrm{~V}$

\section{ACKNOWLEDGMENT}

This work has been partially sponsored by the Spanish "Ministerio de Educación y Ciencia" under the grant DPI20030887-C03-C02.

\section{REFERENCES}

[1] R.C. Bansal, "Three-phase self-excited induction generators: an overview", IEEE Transactions on Energy Conversion, vol. 20, no. 2, pp. 292-299, June 2005.

[2] J.A. Barrado and R. Griñó, "Voltage and frequency control for a selfexcited induction generator using a three-phase four-wire electronic converter", in Proc. Power Electronics and Motion Control Conference, 30 August-1 September 2006, CD-ROM, ISBN: 1-4244-0121-6.

[3] C.A. Quinn and N. Mohan, "Active filtering of harmonic currents in treephase four-wire systems with three-phase and single-phase non-linear loads", Applied Power Electronics Conference, pp. 829-836, 1992.

[4] B. Singh, S. Murthy and S. Gupta, "An improved electronic load controller for self-excited induction generator in micro-hydel applications", in Conf. IEEE Industrial Electronic Society, vol. 3, pp 2741-2746, 2-6 November 2003.

[5] M. Bojrup, P. Karlsson, M. Alaküla and B. Simonsson, "A dual purpose battery charger for electric vehicles", in Proc. Power Electronic Specialist Conference, vol. 1, pp. 565-570, 17-22 May 1998.

[6] P.C. Krause, Analysis of electric machinery, New York: McGraw-Hill, 1986. ISBN: 0-7803-1101-9.

[7] J.A. Barrado and R. Griñó, "Analysis of voltage control for a self-excited induction generator using a three-phase four-wire electronic converter", in Proc. Spanish Portuguese Congress on Electrical Engineering, 30 June-2 July 2005, CD-ROM, ISBN: 84-609-5231-2.

[8] A. Cavini, F. Ronchi and A. Tilli, "Four-wire shunt active filters: optimized design methodology", in Conf. IEEE Industrial Electronic Society, vol. 3, pp. 2288-2293, 2-6 November 2003.

[9] R. Rodríguez, R. Pindado and J. Pou, "Energy control of three-phase four-wire shunt active power filter", in Conf. IEEE Industrial Electronic Society, vol. 2, pp. 1061-1066, 2-6 November 2003.

[10] M. Aredes and L.F.C. Monteiro, "A control strategy for shunt active filter", International Conference on Harmonics and Quality of Power, vol. 2, pp. 472-477, 6-9 October 2002.

[11] M. Karimi-Ghartemani and M.R. Iravani, "A method for synchronization of power electronic converters in polluted and variable frequency environments", IEEE Trans. Power Systems, vol. 19, no. 3, pp. 12631270, August 2004.

[12] B. Singh, K. Al-Haddad and A. Chandra, "Harmonic elimination, reactive power compensation and load balancing in three-phase four-wire electric distribution systems supplying non-linear loads", Electric Power Systems Research, vol. 44, pp. 93-100, 1998. 